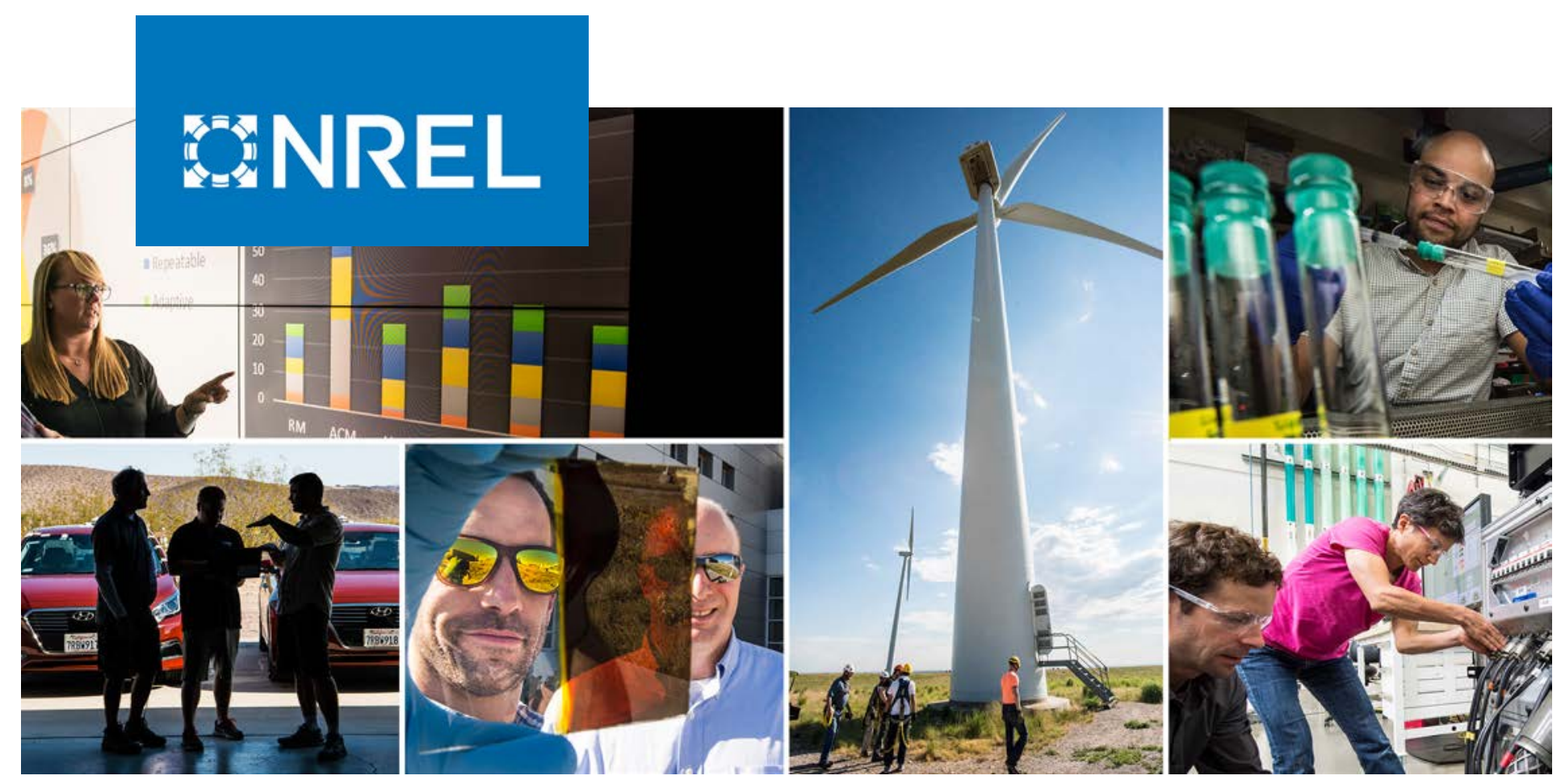

\title{
The Impact of Behind-the-Meter Heterogeneous Distributed Energy Resources on Distribution Grids
}

\section{Preprint}

Priti Paudyal, ${ }^{1}$ Fei Ding, ${ }^{1}$ Shibani Ghosh, ${ }^{1}$ Murali Baggu, ${ }^{1}$ Martha Symko-Davies, ${ }^{1}$ Chris Bilby, ${ }^{2}$ and Bryan Hannegan ${ }^{2}$

${ }^{1}$ National Renewable Energy Laboratory

${ }^{2}$ Holy Cross Energy

Presented at the 47th IEEE Photovoltaic Specialists Conference (PVSC 47) June 15-August 21, 2020

NREL is a national laboratory of the U.S. Department of Energy

Office of Energy Efficiency \& Renewable Energy

Operated by the Alliance for Sustainable Energy, LLC

This report is available at no cost from the National Renewable Energy Laboratory (NREL) at www.nrel.gov/publications.
Conference Paper

NREL/CP-5D00-74736

August 2020 


\title{
GNREL
}

\section{The Impact of Behind-the-Meter} Heterogeneous Distributed Energy Resources on Distribution Grids

\section{Preprint}

Priti Paudyal, ${ }^{1}$ Fei Ding, ${ }^{1}$ Shibani Ghosh, ${ }^{1}$ Murali Baggu, ${ }^{1}$ Martha Symko-Davies,${ }^{1}$ Chris Bilby, ${ }^{2}$ and Bryan Hannegan ${ }^{2}$

\author{
${ }^{1}$ National Renewable Energy Laboratory \\ ${ }^{2}$ Holy Cross Energy
}

\section{Suggested Citation}

Paudyal, Priti, Fei Ding, Shibani Ghosh, Murali Baggu, Martha Symko-Davies, Chris Bilby, and Bryan Hannegan. 2020. The Impact of Behind-the-Meter Heterogeneous Distributed Energy Resources on Distribution Grids: Preprint. Golden, CO: National Renewable Energy Laboratory. NREL/CP-5D00-74736. https://www.nrel.gov/docs/fy20osti/74736.pdf.

(C) 2020 IEEE. Personal use of this material is permitted. Permission from IEEE must be obtained for all other uses, in any current or future media, including reprinting/republishing this material for advertising or promotional purposes, creating new collective works, for resale or redistribution to servers or lists, or reuse of any copyrighted component of this work in other works.

NREL is a national laboratory of the U.S. Department of Energy Office of Energy Efficiency \& Renewable Energy Operated by the Alliance for Sustainable Energy, LLC

This report is available at no cost from the National Renewable Energy Laboratory (NREL) at www.nrel.gov/publications.

Contract No. DE-AC36-08GO28308
Conference Paper NREL/CP-5D00-74736 August 2020

National Renewable Energy Laboratory 15013 Denver West Parkway Golden, CO 80401 303-275-3000 • www.nrel.gov 


\section{NOTICE}

This work was authored in part by the National Renewable Energy Laboratory, operated by Alliance for Sustainable Energy, LLC, for the U.S. Department of Energy (DOE) under Contract No. DE-AC36-08GO28308. Funding provided by U.S. Department of Energy Office of Electricity's Advanced Grid Research division, Advanced Research Projects Agency-Energy (ARPA-E) Network Optimized Distributed Energy Systems (NODES) program, and Holy Cross Energy under a cooperative research and development agreement. The views expressed herein do not necessarily represent the views of the DOE or the U.S. Government.

This report is available at no cost from the National Renewable Energy Laboratory (NREL) at www.nrel.gov/publications.

U.S. Department of Energy (DOE) reports produced after 1991 and a growing number of pre-1991 documents are available free via www.OSTI.gov.

Cover Photos by Dennis Schroeder: (clockwise, left to right) NREL 51934, NREL 45897, NREL 42160, NREL 45891, NREL 48097, NREL 46526.

NREL prints on paper that contains recycled content. 


\section{The Impact of Behind-the-Meter Heterogeneous Distributed Energy Resources on Distribution Grids}

\author{
Priti Paudyal \\ National Renewable Energy Laboratory \\ Golden, CO, USA \\ Priti.Paudyal@nrel.gov \\ Murali Baggu \\ National Renewable Energy Laboratory \\ Golden, CO, USA \\ Murali.Baggu@nrel.gov
}

\author{
Fei Ding \\ National Renewable Energy Laboratory \\ Golden, CO, USA \\ Fei.Ding@nrel.gov \\ Martha Symko-Davies \\ National Renewable Energy Laboratory \\ Golden, CO, USA \\ Martha.Symko.Davies@nrel.gov
}

\author{
Shibani Ghosh \\ National Renewable Energy Laboratory \\ Golden, CO, USA \\ Shibani.Ghosh@nrel.gov \\ Chris Bilby \\ Holy Cross Energy \\ Glenwood Springs, CO, USA
}

\author{
Bryan Hannegan \\ Holy Cross Energy \\ Glenwood Springs, CO, USA
}

\begin{abstract}
The increasing integration of distributed energy resources (DERs) on the electric grid brings new challenges and opportunities for utility grid operations. With the rapid deployment of DERs, there is emerging interest in integrating these controllable devices with utility operations at all levels for monitoring and management. To understand the challenges with increasing behind-the-meter (BTM) DERs and to identify the needs in deploying advanced controls, a comprehensive grid impact study is indispensable. This paper presents the analysis which help visualize the DER impact on the grid, identify the challenges and provides an insight into the new distribution management and control needs to enable reliable and resilient grid operations.
\end{abstract}

Index Terms-Distributed Energy Resource, distribution network, behind-the-meter, voltage profile, OpenDSS.

\section{INTRODUCTION}

The term distributed energy resources (DERs) is defined by the Federal Energy Regulatory Commission [1] as, "a source or sink of power that is located on the distribution system, any subsystem thereof, or behind a customer meter. These resources may include, but are not limited to, electric storage resources, distributed generation, thermal storage, and electric vehicles and their supply equipment". These resources can be owned by utilities, third-party aggregators, or residential consumers as behind-the-meter assets. The integration of DERs has been accelerating in recent years. For example, in 2016, DERs accounted for $2 \%$ of the total installed generation capacity in the United States, and distributed solar photovoltaics (PV) alone represented more than $12 \%$ of new capacity additions [1]. As of 2017, five classes of DERs-distributed $\mathrm{PV}$, small-scale combined heat and power, residential smart thermostats, electric vehicles (EVs), and energy storagecontributed 46.4 GW to the U.S. summer peak [2]. Behindthe-meter DERs can be aggregated and managed to provide services to the distribution grid, including voltage regulation, frequency regulation, and peak load management, etc.

Traditional electric grids were not designed to host DERs, but the deployment of DERs has been significantly increasing. In this context, integrating DER technologies in the existing electric grid is challenging and requires careful planning. It is extremely important to determine the impact of DER deployment on the electric power system for safe and reliable operation. Therefore, grid impact studies help identify the effects and measures/changes that are necessary to make the system suitable for DER integration. OpenDSS, a distribution system simulator, facilitates to conduct such analysis. The physical distribution network can be modeled along with the PV system and energy storage, and load flow analysis can be conducted. Several studies in the literature have presented reviews as well as analyses of the impact assessments of different distributed generation types on the distribution system. In [3], the authors discussed the issues and emerging challenges resulting from the implementation of various smart grid components, including DER integration. In [4], the authors explored power quality issues related to the increasing PV penetration levels on the low-voltage distribution. The impact of high penetration of rooftop PV and the voltage support provided by smart PV inverters were investigated in [5]. Further, the author in [6] proposed a variable-time-step solver for QSTS (Quasi-static time-series) analysis to study the effect of very high distribution-connected PV penetration. Similarly, in [7], the requirement of QSTS analysis to adequately model DER impacts was demonstrated.

This paper studies the impact of different types of behindthe-meter (BTM) DERs-including distributed PV; battery energy storage systems (BESS); heating, ventilation, and airconditioning (HVAC) load; electric water heater (EWH) load; and electric vehicles (EVs)—on a selected utility distribution 
feeder from Colorado, U.S., and we identify the challenges and new control needs to enable reliable and resilient distribution grid operations with increasing high penetration levels of BTM DERs. The contribution of this work includes the modeling of different DERs including $\mathrm{EV}$ to integrate to the real utility distribution feeder, conducting monte carlo simulations to generate the realistic EV charging load, analyzing and quantifying the impact of a mix of BTM DERs on the distribution grid considering the previous year high and low energy consumption days, identifying the voltage issues and critical node points with the incorporation of uncoordinated EV charging, and demonstrating the advantage of having DERs with reduced daily electricity cost.

This paper is organized as follows: Section II presents the models of the BTM DERs, and Section III provides information about the test system. Section IV presents the case study scenarios and simulation results. Finally, Section $\mathrm{V}$ provides the conclusion of the study.

\section{Behind-The-Meter DER Modeling}

\section{A. Distributed Photovoltaic System}

Industry practice for PV inverter operations typically limits the amount of reactive power to be $44 \%$ of the inverter capacity to restrict the inverter power factor to be at least 0.9 . In this paper, the PV panel is sized in such a way that the total annual generation matches $120 \%$ of the total annual load consumption at the same residential location. It is common in the industry to oversize a PV array by using a DC-to-AC (kilowatt) ratio of approximately 1.15 to use the system components to their full capacity [8]. With the release of IEEE 1547-2018 [9], smart inverters equipped with $\mathrm{PV}$ panels are expected to provide both active and reactive power support. Also, oversized PV inverters are expected to provide enough reactive power when needed.

\section{B. Distributed Battery Energy Storage System}

Local control for distributed BESS is designed here to maximize the self-consumption of colocated solar PV units. We assume that the BESS are sized so that their peak kilowatt values are no less than the peak kilowatt ratings of the PV units. Capacity sizing considers commercially available products for these peak kilowatt levels of BESS.

BESS under local control follow PV generation shapes during the daytime, i.e., they do not charge from the grid, but rather from the PV generation. In the afternoon, they start discharging during peak hours (after 5 p.m.), following the net load shape for the house. Both the charging and discharging dispatch algorithms follow the state-of-charge (SoC) constraints (for example, results in the following sections assume that the SoC is limited to between $20 \%-90 \%$ ). These parameters, however, can be configured to reflect the user preferences or other objectives.

\section{Schedulable Load}

Residential loads mainly comprise space heating/cooling, water heating, cooking, clothes washing, drying, lighting, and others. Among these, space heating/cooling and water heating are major power-consuming loads. Also, the HVAC for space heating/cooing and EWH for water heating are the thermal energy storage loads, i.e., they can store energy and serve their purposes even without power for a certain time. So HVACs and EWHs are considered controllable/schedulable loads whose controlled operation can have negligible impact on the residents' daily life. Here, it is considered that the HVAC and EWH of the residential houses are controllable, and all other loads are uncontrollable (base) loads. The modeling and implementation of HVACs and EWHs are explained in the following sections.

1) HVAC Model: An HVAC load has a thermostat that operates within a defined temperature band in an on/off mode. It consumes the rated power when turned on. The room temperature varies within a given deadband around a set-point temperature. The HVAC model adopted from [10] estimates the room temperature for each time step. It considers several detailed factors, such as the previous time-step temperature, outdoor temperature, size of house, heat resistance of windows, and solar radiation. The estimated room temperature for the next time-step $t+1$ is calculated by (1).

$$
T_{t+1}=T_{t}+\Delta t \cdot \frac{G_{t}}{\Delta c}+\Delta t \cdot \frac{C_{A C}}{\Delta c} \cdot \delta_{A C, t}
$$

where $\Delta t$ is the length of time step $t(\mathrm{~h}), T_{t}$ is the room temperature $\left({ }^{\circ} \mathrm{F}\right), G_{t}$ is the heat gain rate of the house $(\mathrm{Btu} / \mathrm{h})$ (explained in detail in [10]), $C_{A C}$ is the cooling/heating capacity $(\mathrm{Btu} / \mathrm{h}), \Delta c$ is the energy required to change the temperature of the air in the room by $1^{\circ} \mathrm{F}\left(\mathrm{Btu} /{ }^{\circ} \mathrm{F}\right)$, and $\delta_{A C, t}$ is the status of the HVAC unit at time $t(0=\mathrm{off}, 1=\mathrm{on})$.

2) Electric Water Heater Model: An EWH load has heating coils that consume rated power when turned on and operate within the defined upper temperature bound and set-point temperature. When the hot water temperature increases to or beyond the upper bound, the coils turn off until the temperature decreases to less than the set-point temperature. The EWH model adopted from [10] calculates the estimated hot water temperature inside the tank. The model depends on several factors, such as inlet water temperature, outlet water flow rate, size of tank, heat resistance of tank, and so on. The estimated outlet water temperature for the next time step $t+1$ is calculated by (2).

$$
\begin{aligned}
T_{\text {out }, t+1} & =\frac{T_{\text {out }, t}\left(V_{\text {tank }}-f_{t} \cdot \Delta t\right)}{V_{\text {tank }}}+\frac{T_{\text {in }} \cdot f_{t} \cdot \Delta t}{V_{\text {tank }}}+ \\
& \frac{1}{8.34}\left[P_{W H, t} \cdot 3412-\frac{A_{\text {tank }} \cdot\left(T_{\text {out }, t}-T_{a}\right)}{R_{\text {tank }}}\right] \cdot \frac{\Delta t}{60} \cdot \frac{1}{V_{\text {tank }}}(2)
\end{aligned}
$$

where $T_{i n}$ is the temperature of inlet water $\left({ }^{\circ} \mathrm{F}\right), T_{a}$ is the room temperature $\left({ }^{\circ} \mathrm{F}\right), P_{W H, t}$ is the power consumed by the EWH at time $t(\mathrm{~kW})$ (product of the rated power, status, and efficiency of the EWH), $f_{t}$ is the hot water flow rate $(\mathrm{gpm})$, $A_{\text {tank }}$ is the surface area of the tank $\left(f t^{2}\right), V_{\text {tank }}$ is the volume of the tank (gal), $R_{\text {tank }}$ is the heat resistance of the tank $\left({ }^{\circ} \mathrm{F}\right.$ $\cdot f t^{2} \cdot \mathrm{h} / \mathrm{Btu}$ ), and $\Delta t$ is the duration of each time-step (min). 


\section{Base Load}

Residential appliances other than the HVAC and EWH are modeled as base loads. Each house has several appliances, such as a television, iron, toaster, dishwasher, clothes washer, dryer, computers, cookers, and lighting. In this study, an average daily power profile of a typical residential house load in Colorado is obtained from Xcel Energy [11] for each month. On top of the monthly average load profile, other loads as mentioned are added randomly at typical time periods in a day, referred from [12], and a new power profile is generated. The generated base power profiles for each house are timevarying and different from each other. For example, in the average weekday power profile shown by the blue curve in Fig. 1, a dishwasher is added from 7:09 a.m. to 8:12 a.m., a washing machine from 6:34 a.m. to 7:47 a.m., a hair dryer from 7:09 p.m. to 7:18 p.m., a stove top from 5:09 p.m. to 5:52 p.m., and a PC monitor from 7:19 p.m. to 8:27 p.m. The inclusion of these loads at different times in a day creates the base load, the red curve in Fig. 1.

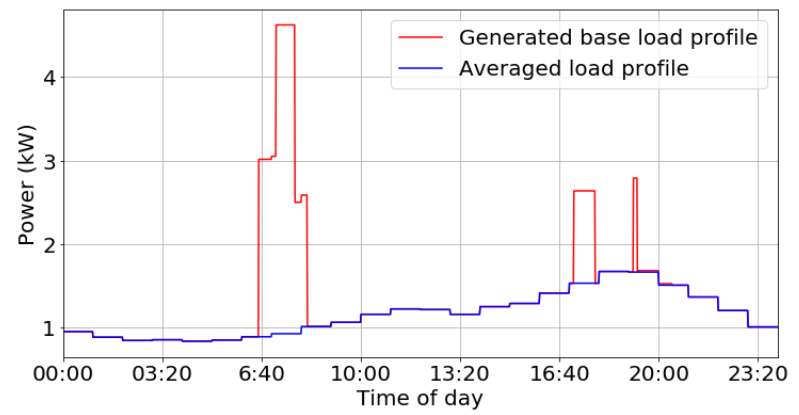

Fig. 1. Base-load profile generated for a house along with the average daily residential load profile of Colorado.

\section{TEST SYSTEM}

\section{A. Feeder Characteristics}

A distribution feeder located in Colorado is modeled using OpenDSS (Fig. 2) and is the test system in this work. This feeder has a peak load of approximately 4.5 MW and nearly 4,000 three-phase nodes. More than 160 residential customers are connected on this feeder, and all of them have electric loads, thus making a suitable test set to conduct the analyses described in this work. We assume that these customers have flexible HVAC and EWH loads as well as PV and storage units on their premises that can serve as controllable local assets. Storage units are sized to capture the PV generation so that possible overvoltage scenarios can be averted. PV penetration on this feeder is hypothetically increased to help evaluate the worst possible impact on the existing grid condition. The feeder model uses yearly load shape and PV shapes for spot loads and PV units from the actual 1-year advanced metering infrastructure (AMI) measurements.

\section{B. Residential DERs}

Multiple types of loads exist on the feeder. According to the AMI measurements provided by the utility partner, load profiles labeled "all-electric" with a peak less than $15 \mathrm{~kW}$

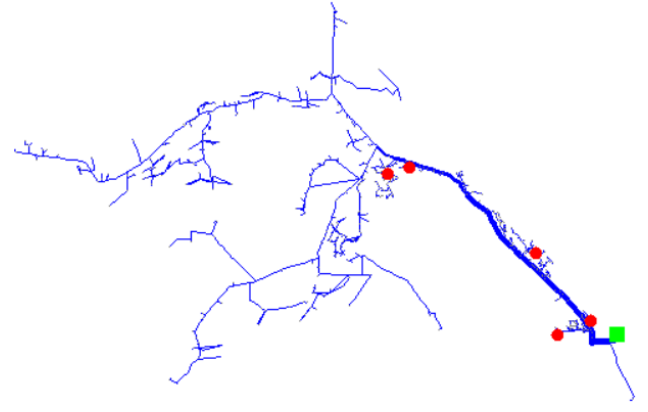

Fig. 2. Feeder topology for the selected network located in Colorado. The green square represents the substation, and the red dots are measurement locations for which voltage results are shown in following sections.

are chosen as the all-electric residential homes for modeling. These homes are modeled to have DERs, i.e., PV, BESS, and EV along with flexible loads, and base loads. All DERs follow the models described in Section II.

\section{Electric Vehicles}

EV load has both spatial and temporal uncertainties, and it depends on the number of EVs, charging locations, charging time, and the initial SoC. In this paper, we model different EV penetration levels and types of EVs, and we use the National Household Travel Survey data [13] to model the driving behavior (arrive/leave home time, mileage driven). Level 2 charging is assumed to be available at all all-electric residential homes. Three work locations and public locations are modeled to install Level 3 charging stations. These locations are based on a screening study the utility has done to identify workplace and public locations best able to accommodate Level $2(240-\mathrm{V})$ and Level 3 (DC fast charging). In this paper, we assume that EVs can charge at home, work, or public locations depending on their own schedules and time of day.

\section{DER GRID IMPACT STUDY}

The impact of a mix of DERs on the distribution feeder is analyzed by performing multiple time-series simulations for different days in a year. The variability in the distribution voltage and substation power is investigated. Also, the difference in the daily electricity cost of all-electric residential homes resulting from the addition of the BTM DERs is explored.

\section{A. Scenario Description}

Two different days in different seasons are chosen: January 27, 2017 (maximum load day observed), and May 3, 2017 (minimum load day). Different scenarios for the time-series simulation studies are explained as follows.

o S1: System with modeled residential loads and existing PV (No PV no ES) - In this scenario, the system has its original resources along with 164 modeled residential loads. Different sets of the house parameters are assigned for different all-electric residential homes. The temperature setting preferences for each house's HVAC and EWH are randomly assigned and adjusted according to the occupancy time. The 
time-series load-flow analysis simulation is conducted with these considerations.

o S2: Add additional PV for the electric homes (With PV no ES) - In this scenario, additional distributed PV is installed in the all-electric residential homes with modeled loads. All these homes have different PV generation capacities based on their annual energy consumption. The system is simulated by adding PV to the S1 scenario, and the effects on the system are analyzed.

o S3: Add BESS (With PV with ES)_BESS are installed in the all-electric residential homes where the PV generation is greater than $5 \mathrm{~kW}$. BESS are allowed to charge only when there is PV output and discharge during afternoon/evening hours when peak loads are common to occur.

o S4: Add EV (With PV, ES and EV)—Each all-electric residential home is assumed to have at least $1 \mathrm{EV}$. EVs can charge at homes, workplaces, or public locations. Because EV loads are both spatially and temporally uncertain, 100 simulations are performed to explore the grid impact of stochastic EV loads.

\section{B. Simulation Settings}

For the simulation studies, the available standard values are used for residential HVAC and EWH model parameters, such as power ratings, house parameters, and tank sizes. The room temperature set-points for different houses vary from $66^{\circ} \mathrm{F}$ to $72.5^{\circ} \mathrm{F}$, and the deadband varies from $2^{\circ} \mathrm{F}$ to $3^{\circ} \mathrm{F}$. Similarly, the water temperature set-points and deadband vary from $118^{\circ} \mathrm{F}$ to $125^{\circ} \mathrm{F}$ and $8^{\circ} \mathrm{F}$ to $12^{\circ} \mathrm{F}$, respectively. Because the selected two days are weekdays, the room temperature set-points are decreased to $60^{\circ} \mathrm{F}$ from 10 a.m. until 4 p.m., assuming that nobody would be home during that time. The actual outdoor temperature and solar radiation data required for the HVAC model are taken from [14], for the considered area in Colorado for January 27 and May 3, 2017. The time-of-use (TOU) tariff rate is considered for calculating the electricity bill for allelectric residential homes_-peak time rate: $20 \mathrm{c} / k W h$ (from 6 a.m. until 9 a.m. and 4 p.m. until 9 p.m.); and off-peak rate: 5 c $/ k W h$ (except peak hours). The simulation time step is 30 minutes.

\section{Simulation Result}

Fig. 3 presents the aggregated total load, PV, BESS power, along with the BESS average SoC for January 27 for 20 households. The blue trace represents the total load for these households; the net PV (red) and net battery (green) represent the aggregated PV power and corresponding battery charging/discharging levels. The average SoC for these $20 \mathrm{BESS}$ are plotted in Fig. 3 (black trace). The locally controlled BESS, as described in Section II, start charging from sunrise following the PV profile, and the load-following discharging begins during peak evening hours (5 p.m.-10 p.m.). The charging/discharging patterns depend on the SoC limits. For example, in Fig. 3, the charging stops before midday because the SoC saturates, and the discharging of these BESS can follow the load profiles only for 3 hours until the SoC reaches the lower limit set-point of $20 \%$.

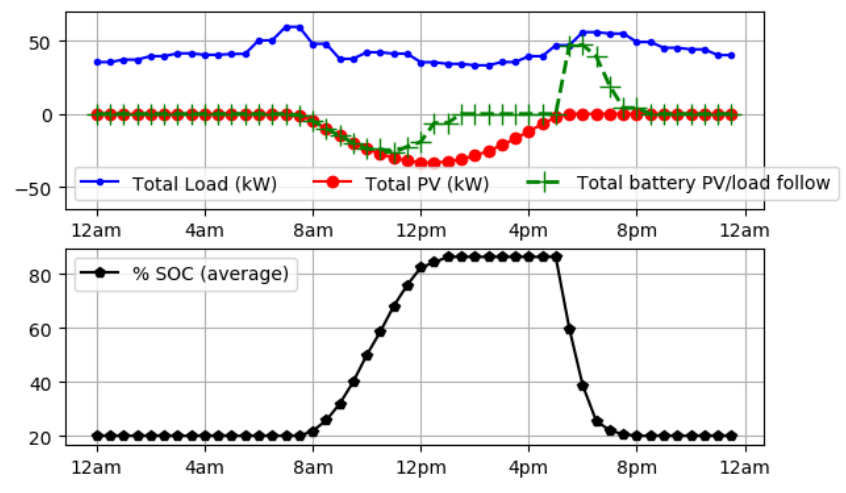

Fig. 3. BESS charging/discharging profiles for January 27 (considering 20 households).

The feeder voltage profiles considering scenarios S1, S2, and S3 are obtained. Fig. 4a and Fig. 4b show the voltages at 1 p.m. on January 27 and May 3, when the PV generation was high. The voltages are within the standard limits of $[0.95$, 1.05] for the three scenarios and both days as well. Fig. 5 represents 1-day voltage at one randomly selected node for the scenarios S1, S2, and S3, respectively, for January 27 and May 3. Fig. 5b portrays higher voltage compared to Fig. 5a because of a lower load demand and higher PV output. With the addition of residential PV (S2), the voltage increases with PV generation; whereas from 11:30 a.m. until 3:00 p.m., it is observed that this node voltage decreases compared to $\mathrm{S} 1$. This is because during this period of the day the load is reduced but there is high PV generation which leads to increased voltage, so the local voltage regulator's tap position changes to regulate the voltage within the permissible limit. With the addition of BESS (S3), the regulator setting was not required to change for January 27 since the BESS consumed the extra PV generation during the day time. While for May 3, minimum load day, the voltage was still high enough so the regulator had to adjust its setting. The BESS discharged during the afternoon when the load increased and there was no PV output. Thus, this demonstrates that the addition of energy storage helps in the voltage regulation.

Fig. 6 represents the distribution of the all-electric residential homes' electricity costs for January 27 for the three scenarios - S1, S2, S3 - and for the case where the set points of the HVAC and EWH are reduced during peak price periods (with TOU effect) to reduce the energy consumption during those hours. The time-of-use (TOU) tariff rate is applied for all the cases. Considering no PV and no energy storage as the base case, the electricity bill decreases by $20.7 \%$ on average for the case with PV and BESS. Moreover, in addition to adding PV and BESS, when the HVAC and EWH reduce their power consumption (reducing the set points to $63^{\circ} \mathrm{F}$ ) during peak price periods, the energy cost is further reduced (with TOU effect in Fig. 6). Since the HVAC and EWH set points were decreased during the day time in scenarios $\mathrm{S} 1, \mathrm{~S} 2$, and $\mathrm{S} 3$, 


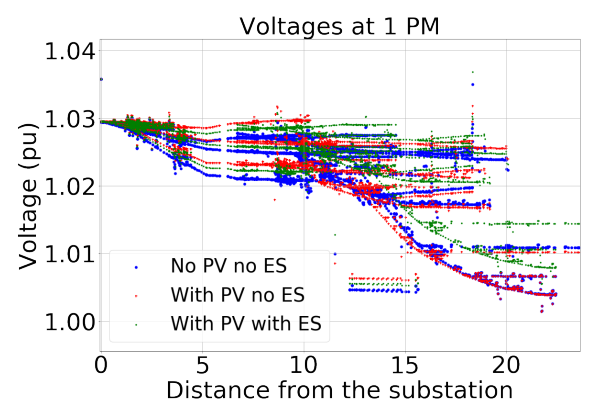

(a)

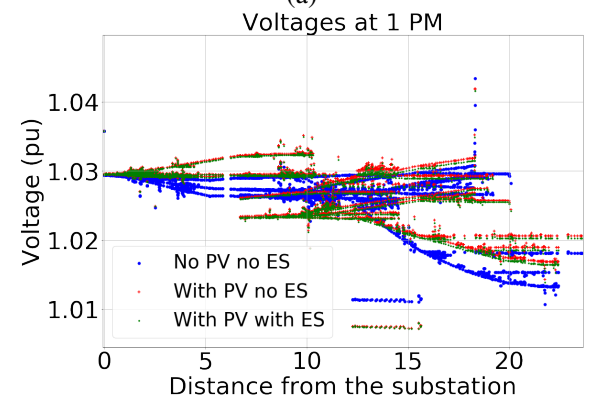

(b)

Fig. 4. Node voltages at 1 p.m. according to the distance from the substation (a) for January 27, 2017, and (b) for May 3, 2017.

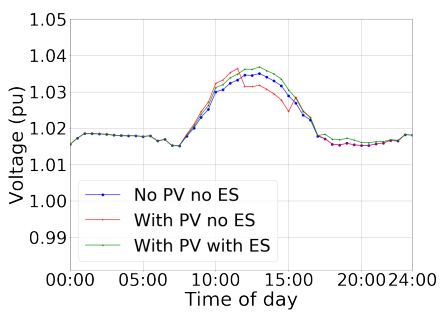

(a)

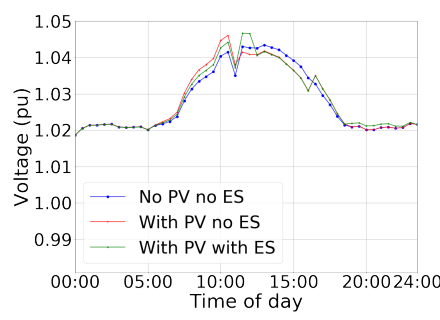

(b)
Fig. 5. One-day voltage at one selected node for (a) January 27 and (b) May $3,2017$.

there is a small difference in the electricity cost between $\mathrm{S} 3$ and the case where HVAC and EWH respond to the TOU price. Likewise, if the BESS control were automated to respond to the price signal, a significant cost saving could be observed.

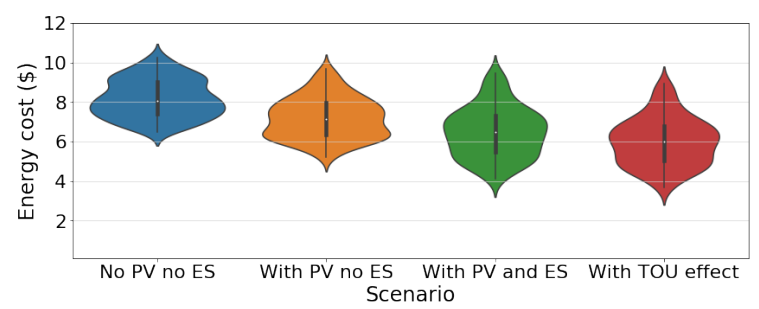

Fig. 6. Comparison of electricity cost for January 27 considering the three scenarios for the 164 all-electric residential homes.

Fig. 7 depicts the total PV generation and the total EV charging power (one of 100 samples) for Jan 27. The top blue curve represents the $\mathrm{kW}$ power from PV that already existed in the feeder and there is no residential PV added. The red curve represents the total PV power after adding residential PV for this analysis. Fig. 8 shows the total substation power for Jan 27 and May 3 considering all four scenarios. The addition of EV loads without coordinated charging could increase the total substation power significantly.

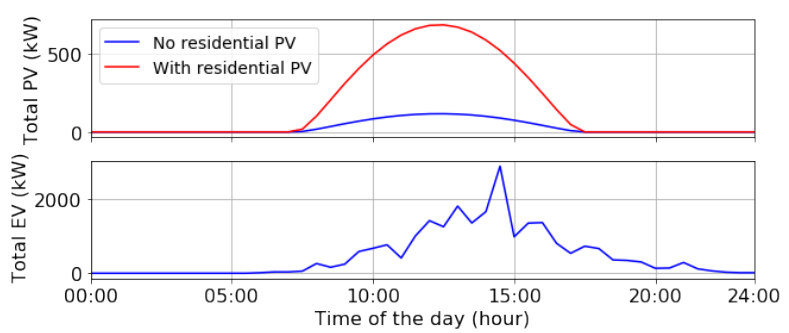

Fig. 7. Total PV power and random estimated EV power for January 27, 2017.

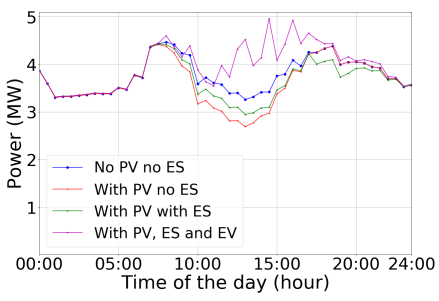

(a)

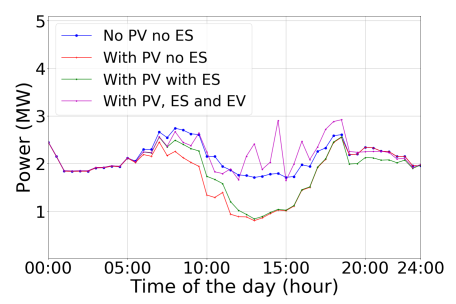

(b)
Fig. 8. Total substation power considering all four scenarios for (a) January 27 and (b) May 3, 2017.

Fig. 9 shows the distribution of all node voltages. Because 100 simulations were conducted to analyze the effect of stochastic EV loads, different simulation runs have varying effects on the voltage, as observed in Fig. 9. It is noteworthy that EV loads without coordinated charging strategy are likely to cause voltage violations on this particular feeder. The voltages on the network with uncontrolled EV loads can also be visualized by the distribution plot of the node voltages portrayed in Fig. 10. Some of these selected node voltages are beyond the permissible limits.

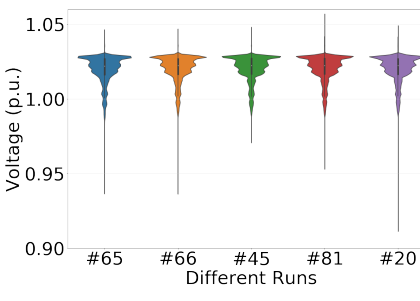

(a)

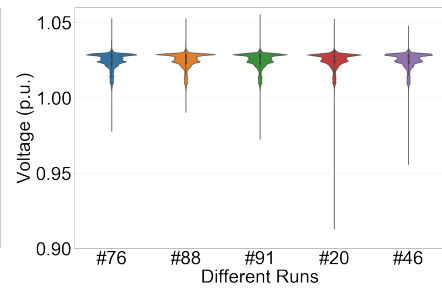

(b)
Fig. 9. Voltage distribution for different simulation runs considering EV loads for (a) January 27 and (b) May 3, 2017.

The average, minimum, and maximum substation power obtained for $100 \mathrm{EV}$ simulation studies is represented by Fig. 11. There are considerable changes in both the maximum and minimum substation power with the addition of the EV load. The scenario that yields the maximum value might 


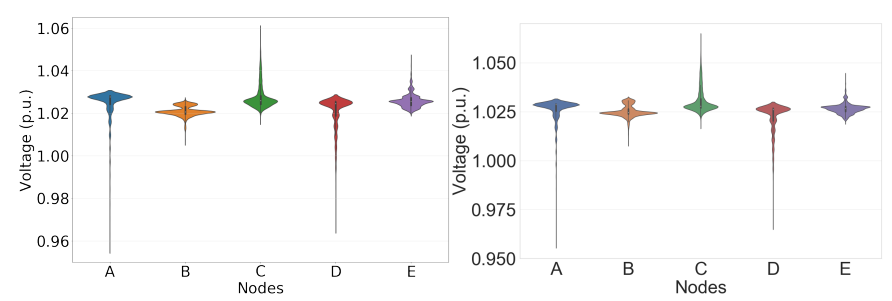

(a)

(b)

Fig. 10. Voltage distribution of selected random nodes considering different EV runs for (a) January 27 and (b) May 3, 2017.

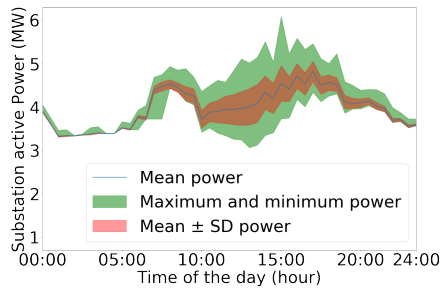

(a)

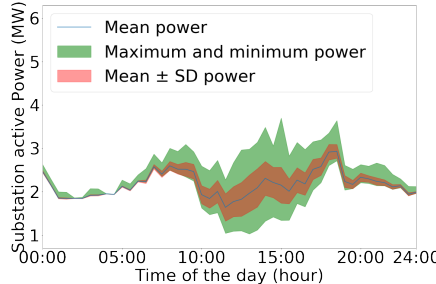

(b)
Fig. 11. Substation power considering different EV runs for (a) January 27 and (b) May 3, 2017.

exceed the total load limit of the substation transformer and degrade the power quality as well as the transformer life.

\section{CONCLUSIONS}

This paper investigated the effect of deploying a mix of DERs in a utility distribution feeder in terms of system voltage profile, substation power, and electricity cost to the customers. Modeling the behind-the-meter heterogeneous DERs in the network was discussed. Multiple time-series simulations were performed considering four different scenarios and two different days of a year to capture the worst-case scenarios. The voltage profile of the considered network appeared to be within the permissible limits for the scenarios where there were flexible loads, distributed PV, and BESS; however, with the integration of uncontrolled EV charging, the feeder voltages were beyond the permissible limits for almost half of the 100 simulation runs. This study also helped to identify the critical nodes which are likely to be affected by the EV deployment. Thus, to deploy EVs in the feeder, there is a need to implement distribution management and control, which is the subject of future work. Compared to a base case with no PV and no BESS, electricity costs for all-electric residential consumers with PV and BESS were reduced on average by $20.7 \%$ when those DERs were combined with TOU rates.

\section{ACKNOWLEDGEMENT}

This work was supported by Alliance for Sustainable Energy, LLC, the manager and operator of the National Renewable Energy Laboratory for the U.S. Department of Energy (DOE) under Contract No. DE-AC36-08GO28308. Funding provided by U.S. Department of Energy Office of Electricity's Advanced Grid Research division, Advanced Research Projects Agency-Energy (ARPA-E) Network Optimized
Distributed Energy Systems program, and Holy Cross Energy under a cooperative research and development agreement. The views expressed in the article do not necessarily represent the views of the DOE or the U.S. Government. The U.S. Government retains and the publisher, by accepting the article for publication, acknowledges that the U.S. Government retains a nonexclusive, paid-up, irrevocable, worldwide license to publish or reproduce the published form of this work, or allow others to do so, for U.S. Government purposes.

\section{REFERENCES}

[1] Distributed Energy Resources Technical Considerations for the Bulk Power System, Feb 2018. [Online]. Available: https://www.ferc.gov/ CalendarFiles/20180215112833-der-report.pdf

[2] G. M. (GTM), "Distributed energy poised for explosive growth on the U.S. grid." [Online] Available: https://www.greentechmedia.com/articles/read/ distributed-energy-poised-for-explosive-growth-on-the-us-grid\#gs. $08 \mathrm{~g} 2 \mathrm{n} 2 . /$

[3] S. Kakran and S. Chanana, "Smart operations of smart grids integrated with distributed generation: A review," Renewable and Sustainable Energy Reviews, vol. 81, pp. 524 - 535, 2018. [Online]. Available: http://www.sciencedirect.com/science/article/pii/S1364032117311188

[4] C. Gonzalez, J. Geuns, S. Weckx, T. Wijnhoven, P. Vingerhoets, T. De Rybel, and J. Driesen, "LV distribution network feeders in Belgium and power quality issues due to increasing PV penetration levels," in 2012 3rd IEEE PES Innovative Smart Grid Technologies Europe (ISGT Europe), Oct 2012, pp. 1-8.

[5] F. Ding, A. Pratt, T. Bialek, F. Bell, M. McCarty, K. Atef, A. Nagarajan, and P. Gotseff, "Voltage support study of smart PV inverters on a highphotovoltaic penetration utility distribution feeder," 06 2017, pp. 1-6.

[6] B. Mather, "Fast determination of distribution-connected PV impacts using a variable-time-step quasi-static time-series approach," in 2017 IEEE 44th Photovoltaic Specialist Conference (PVSC), June 2017, pp. 1561-1566.

[7] M. J. Reno, J. Deboever, and B. Mather, "Motivation and requirements for quasi-static time series (QSTS) for distribution system analysis," in 2017 IEEE Power Energy Society General Meeting, July 2017, pp. 1-5.

[8] [Online]. Available: https://solarprofessional.com/articles/ design-installation/optimal-pv-to-inverter-sizing-ratio\#.XHx-ui2ZNE4.

[9] I. S. 1547-2018, "IEEE standard for interconnection and interoperability of distributed energy resources with associated electric power systems interfaces," February 2018.

[10] S. Shao, M. Pipattanasomporn, and S. Rahman, "Development of physical-based demand response-enabled residential load models," IEEE Transactions on Power Systems, vol. 28, no. 2, pp. 607-614, 2013.

[11] 2016 Electric Resoure Plan, May 2016, vol. 2. [Online]. Available: https://www.xcelenergy.com/staticfiles/xe/PDF/AttachmentAKJ-1.pdf

[12] O. Elma and U. S. Selamoğullar, "A survey of a residential load profile for demand side management systems," in 2017 IEEE International Conference on Smart Energy Grid Engineering (SEGE), Aug 2017, pp. 85-89.

[13] F. H. A. U.S. Department of Transportation, "2017 national household travel survey." [Online]. Available: http://nhts.ornl.gov

[14] "National solar radiation data base." [Online]. Available: https: //rredc.nrel.gov/solar/old_data/nsrdb/ 